INPE ePrint: sid.inpe.br/yolanda/2004/11.23.09.41 v1 2004-11-24

IAC-04-IAF-I.6.10

\title{
EXPERIMENTAL ANALYSIS OF UNIFORMITY AND MEASUREMENT OF ABSORBED THERMAL LOADS IMPOSED BY A TUNGSTEN FILAMENT LAMP ON A RADIOMETER PLATE
}

\author{
Marcio Bueno dos Santos \\ Instituto Nacional de Pesquisas Espaciais (INPE) \\ Laboratório de Integração e Testes (LIT) \\ São José dos Campos - SP - Brazil \\ bueno@lit.inpe.br \\ Eduardo de Oliveira Pontes \\ Instituto Nacional de Pesquisas Espaciais (INPE) \\ Laboratório de Integração e Testes (LIT) \\ São José dos Campos - SP - Brazil \\ eduardo@lit.inpe.br
}

\author{
Ezio Castejon Garcia \\ Instituto Tecnológico de Aeronáutica (ITA) \\ Laboratório de Integração e Testes (LIT-INPE) \\ São José dos Campos - SP - Brazil \\ ezio@ita.br \\ Rose Mary do Prado Demori \\ Instituto Nacional de Pesquisas Espaciais (INPE) \\ Laboratório de Integração e Testes (LIT) \\ São José dos Campos - SP - Brazil \\ demori@lit.inpe.br
}

\begin{abstract}
This paper deals with the development and manufacturing of a radiometer plate to be used in space simulation tests of space systems to measure and verify the uniformity of absorbed heat flux imposed by a Tungsten Filament Lamp. The radiometer plate is composed of an aluminum plate $(670 \times 550 \mathrm{~mm})$, on which 49 radiometers are placed, black painted square copper plates $(39 \times 39 \times 0.6 \mathrm{~mm})$. On each radiometer a thermocouple was installed on the opposite surface to that being measured and these were isolated from the aluminum plate by nylon strands $(\varnothing 0.20 \mathrm{~mm}) \mathrm{MLI}$ (isolating shrouds). In order to install the lamp a vertical rod was placed at the center of one of the extremities of the aluminum plate and to this rod a horizontal rod was connected which made it possible to place the lamp in central position. Preliminary checks of flux and uniformity were carried out at environmental conditions in the Laboratory. The principal results were obtained in a high vacuum environment $\cong 10^{-7}$ Torr) in a $1 \times 1 \mathrm{~m}$ thermal vacuum chamber. To guarantee that the thermal loads emanated only from the lamp, the chamber was kept at a temperature of $--180^{\circ} \mathrm{C}$. Several tests were carried out which varied the height of the lamp to the plate as well as the wattage $(125,250,375,450,500 \mathrm{~W})$. The Laboratory's data acquisition system was used to obtain the temperature data of each radiometer. This system handles 500 measuring channels with acquisition at 30 seconds intervals. From this information the heat fluxes are calculated and presented in the form of graphs. From the results obtained it was possible to evaluate which wattage and position of the lamp provided the best distribution of absorbed heat flux by a space system thermal control surface.
\end{abstract}

\section{INTRODUCTION}

The basic aim of Space Simulation (SS) is to qualify the satellite, or a given spacecraft device so that these may operate reliably in space. The simulation techniques differ from one another basically according to the experimental arrangement used in the imposition of the heat source and the space background. The main techniques are: Solar simulation (the use of a simulator equipped with Xenon lamps), as described by Nuss [5]; Tungsten Filament Lamps (TFL), which operate in the near infrared range (Messidoro et al. [4]); Heating Plates (Cardoso \& Garcia, [2]); Skin Heaters (Ramos et al. [6]); A combination of techniques, as presented by , Braig et al. [1]. The skin heater and heating plate techniques are applied in the far infrared radiation spectrum, which is out of the solar spectrum range, to which a given satellite is exposed to during its orbital life. The use of solar simulation is the most adequate because of the closeness of the solar spectrum; however, the high cost of a simulator is not viable in the light of the present Brazilian economic situation. For this reason, Tungsten Filament Lamp (TFL) simulation, where the high tungsten filament temperature $(2.500 \mathrm{~K})$ produces a spectrum closer to that the solar spectrum (Messidoro et al., [4]), has become an attractive alternative. In order to develop this space simulation technique which uses tungsten filament lamps as a source of thermal radiation, the Laboratory of Integration and Tests (LIT) thermal vacuum test group has projected and manufactured an 
experimental apparatus which consists of a radiometer plate and a Tungsten Filament Lamp, Research Inc. 500T3/CL. This apparatus made it possible to study the behaviour of these lamps in terms of uniformity and intensity. Preliminary tests of flux and uniformity were carried out at Laboratory environmental conditions. The principal results were obtained in a high vacuum environment $\left(\cong 10^{-7}\right.$ Torr) in a $1 \times 1 \mathrm{~m}$. thermal vacuum chamber. In order to guarantee that the thermal loads emanated only from the lamp, the chamber was kept at a temperature of $-180^{\circ} \mathrm{C}$. Several tests were carried out altering both the height and wattage of the lamp. In order to measure the temperature data from each radiometer, the LIT data acquisition system, which handles 500 measuring channels with acquisition at 30 seconds intervals, was used. From this information the heat fluxes are calculated and presented in the form of graphs. From the results obtained it was possible to evaluate the position and wattage of the lamp, which provides the best distribution of absorbed heat flux by a space system thermal control surface

\section{EXPERIMENTAL APPARATUS}

In order to study the behaviour of these tungsten filament lamps in terms of uniformity and intensity an experimental apparatus was set up (figure 1), which consisted of a radiometer plate and a lamp and reflector set. The radiometer plate is composed of an aluminium plate on which 56 radiometers are placed. In order to install the lamp a vertical rod was placed at the center of one of the extremities of the aluminium plate, which made it possible to place the lamp in a central position.

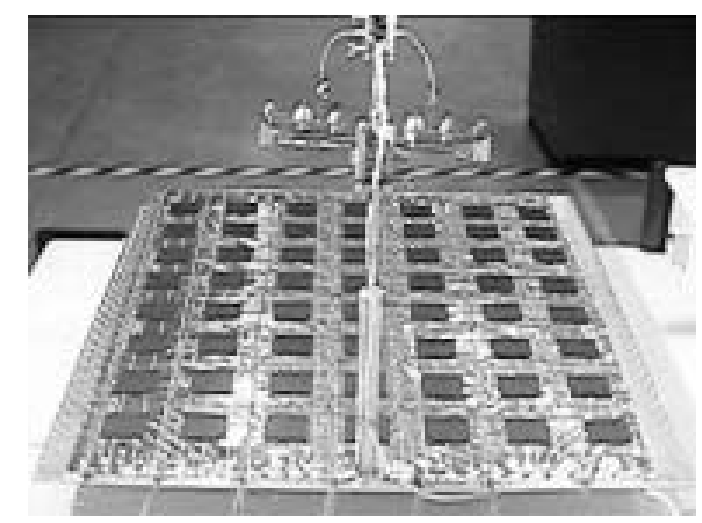

Fig. 1: Experimental apparatus.

\subsection{The Radiometer Plate}

The radiometer plate, Figure (2), is composed of a rectangular aluminium plate $670 \mathrm{~mm}$ long by $550 \mathrm{~mm}$ wide, on which 56 radiometers were placed, along with black painted square copper plates $(39 \times 39 \times 0.6$ $\mathrm{mm}$ ), (PU1 MAP with $50 \mu \mathrm{m}$ thickness, $\varepsilon=0.884$ and $\alpha=0.926)$. On the opposite side to that being measured, a thermocouple was installed on each radiometer. These radiometers were thermally isolated from the aluminium plate by nylon strands $(\varnothing 0.20 \mathrm{~mm})$ and MLI (isolating shrouds). The assembly of the radiometers on the plate, along the $\mathrm{x}$-and $\mathrm{y}$ coordinates, follows a spacing of $70 \mathrm{~mm}$ in relation to the center of each radiometer. The radiometers were produced in LIT/INPE, which has specialized tools available for the production of MLI, machining, measurement of optical properties and a contamination analysis laboratory and painting facilities.

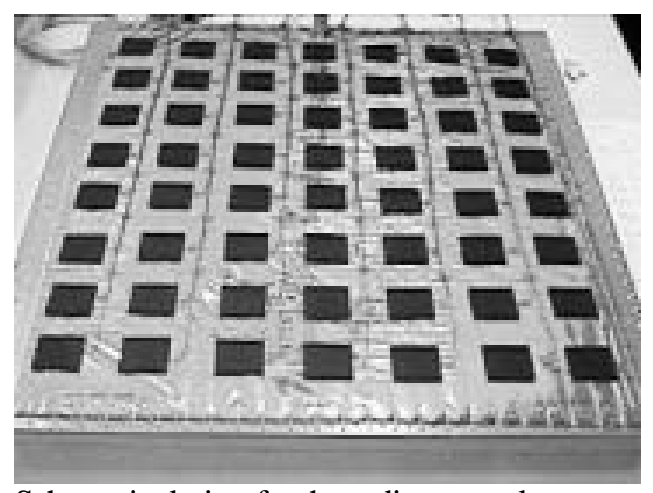

Fig. 2: Schematic design for the radiometer plate.

The principle steps in the production process of the radiometer plate is as follows (Figure 3): Production and coating of the aluminium plate and MLI; attachment of the nylon strands; manufacturing of the copper plates (radiometer sensors); painted black on the measuring side (carried out at the Painting Laboratory LIT, which guarantees the same conditions and characteristics as satellite surfaces); attachment of the thermocouples to the back of the copper plates (the same technique employed when testing satellites during Space Simulation tests is used); precision assembly of the radiometers on the aluminium plate (precision bonding of the radiometers to the nylon strands so there is no contact between any of them, consequently minimizing losses.).

\subsection{Tungsten Filament Lamp}

In order to establish an exact position for the lamp and reflector (5236.5 golded reflector) set in relation the radiometer plate, a mechanical device for positioning the lamp was devised (figure 4). This device is made up of: a vertical circular rod with an articulation joint soldered to the center of one of the extremities of the aluminium plate; and a articulated arm with two (2) degrees of 
freedom ( $\mathrm{x}$ and $\mathrm{y}$ ), composed of circular rods, spheres and articulation joints. The third degree of freedom of the device $(\mathrm{z})$ is performed by the attachment of the arm to the articulation joint of the vertical rod. In this way it was possible to vary and guarantee the position of the lamp. Figure 5 shows the positioning of the lamp in relation to the radiometer.
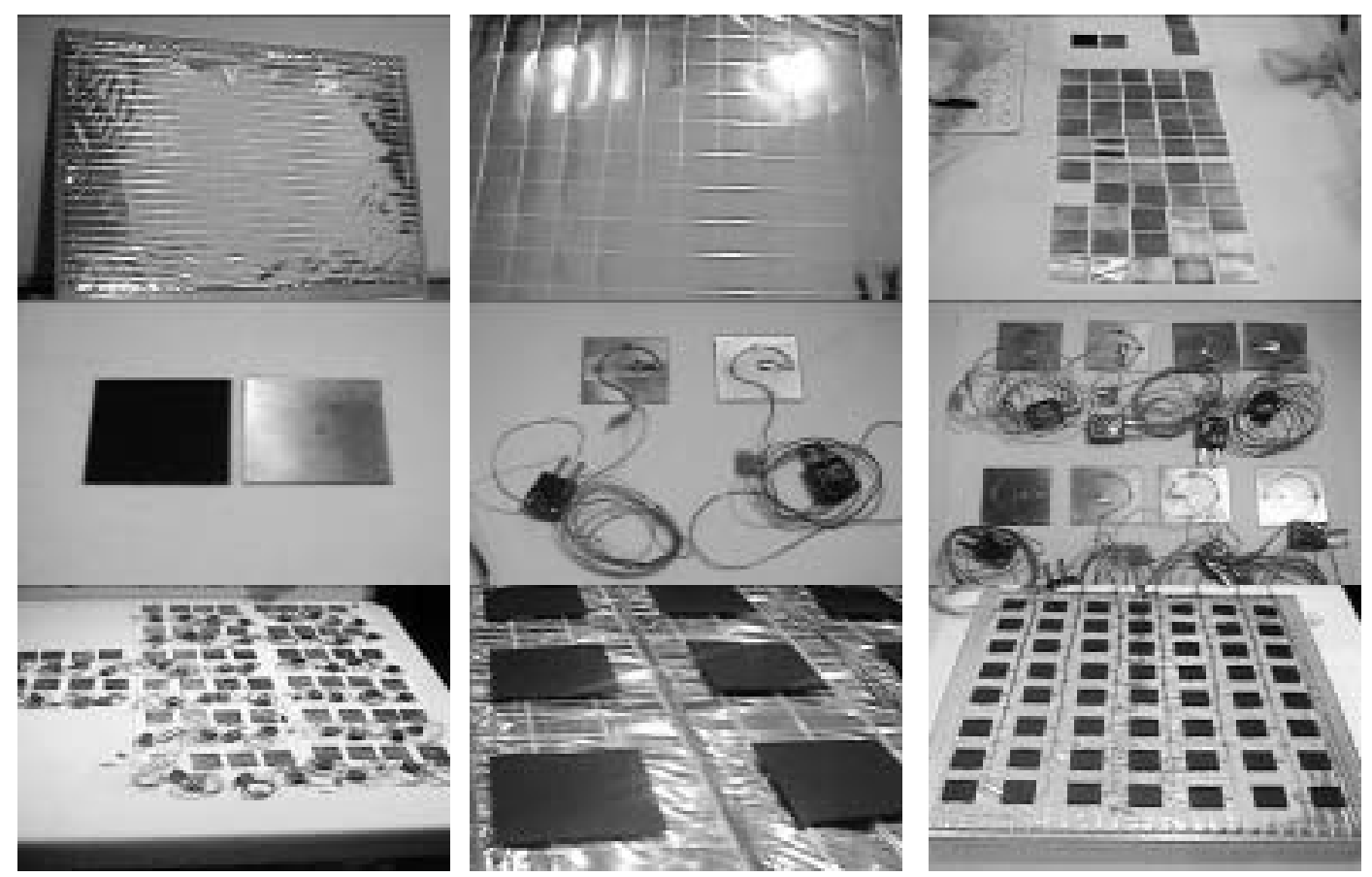

Fig. 3: Manufacturing process of the radiometer plate.
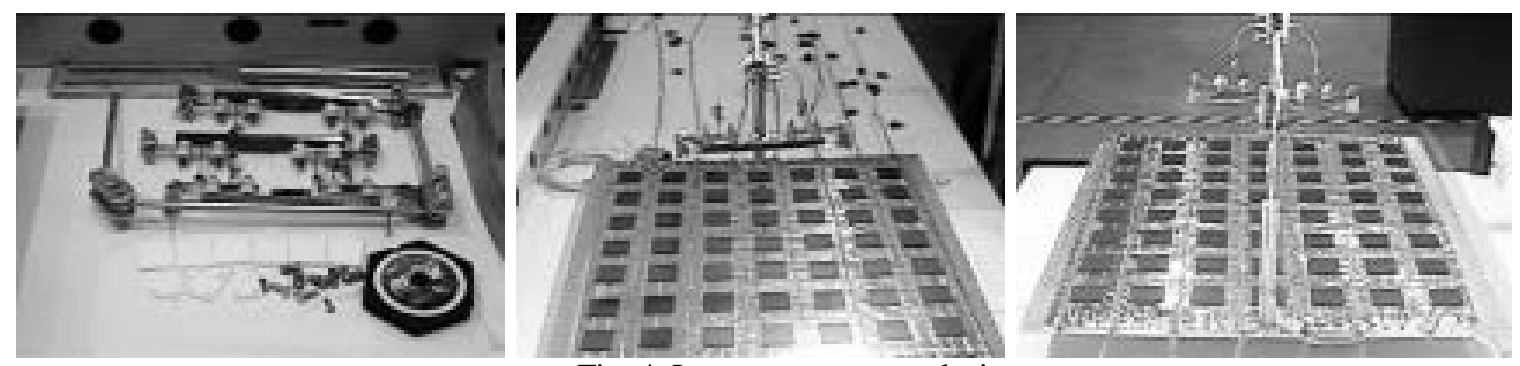

Fig. 4: Lamp arrangement device.

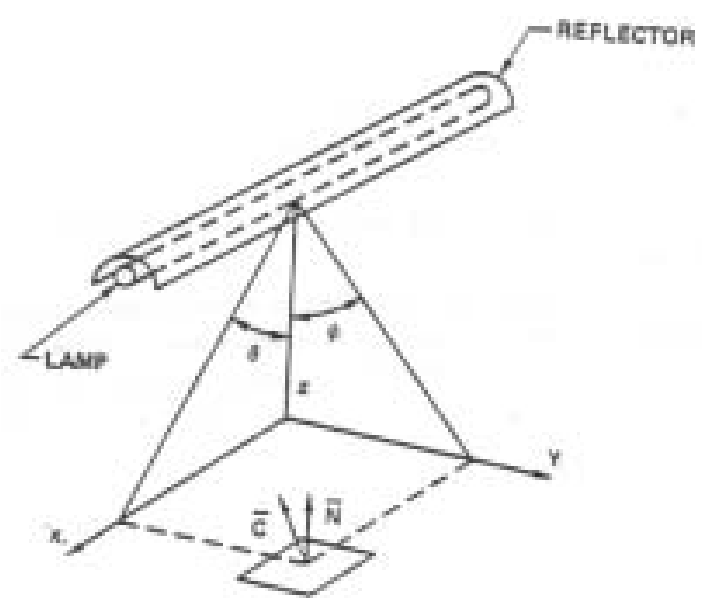


Fig. 5: Positioning of the lamp.

Specification of the lamp used in the apparatus and experimental test is as follows:

- $\quad$ Type

500T3/CL Research Inc, Tungsten Filament Wire, T3 Quartz Lamp

- Overall Length

224(mm)- 8.81 (inches)

- Lighted Length

127(mm) 5 (inches)

- Rated Voltage

$120 \mathrm{~V}$

- Current at Rated Voltage

4.17Amps

- Total Power Dissipated at Rated Voltage 500W

- Average Life

5000 hours

- Color Temperature

$2500 \mathrm{~K}$

- Possible Corona Region in Dry Air

None

- Brightness

Bright White

- Usual Size, Inches (mm)

0.375 or Dia. Tube(9.525)

- Usual Range of Peak Energy Wavelength 0.89 to 1.5 Microns

- Usual Range of Relative Energy

- Distribution Radiation

- Radiation

- Convection
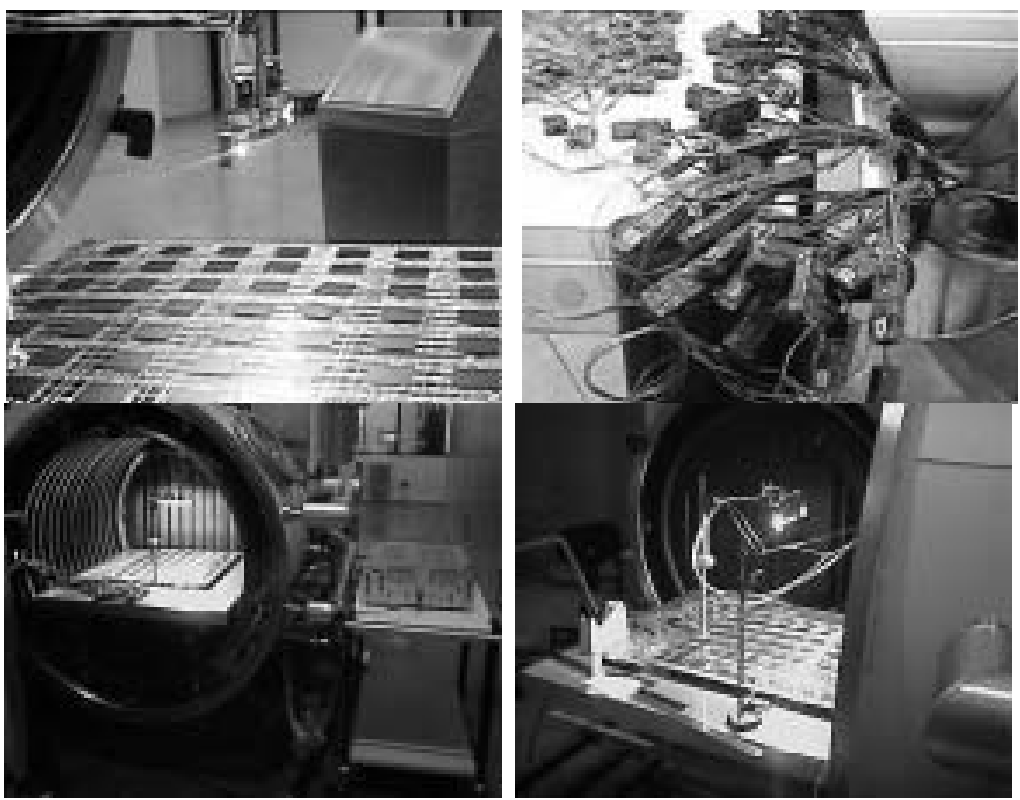

Fig. 6: Experimental arrangement.

\section{2 to $86 \%$}

28 to $14 \%$
- Relative Response to Heat-up

- Relative Response to Cool-down

- Ruggedness

- Mechanical Shock

- Thermal Shock

\section{EXPERIMENTAL TEST}

In order to discover how the lamp acts as a source of thermal radiation in terms of intensity and uniformity some experimental tests were carried out using the LIT 785 liter thermal vacuum chamber. To get a better analysis of the results it was considered that the radiometer plate was composed of only 49 of the original 56 so as to have a square (the last line was not considered due to vertical support for the lamp). For the purpose of obtaining symmetry of the results the lamp was placed on the radiometer plate in a position so that its center coincided with the center of the radiometer plate. Figure (6) shows the arrangement used during the experimental test.

\author{
Seconds \\ Seconds \\ Good \\ Excellent
}

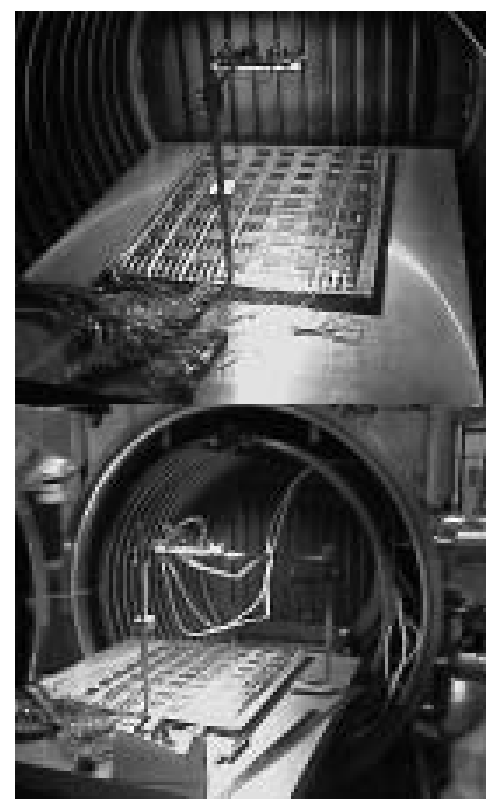

During tests the thermal vacuum chamber was kept at high vacuum ( $\cong 10^{-7}$ Torr), and to guarantee that the thermal loads originated only from the lamps the chamber was kept at a temperature of $-180^{\circ} \mathrm{C}$. Several tests were carried out varying both the height and wattage of the lamp. A Tectrol DC power source of $1000 \mathrm{~W}$ was used to control the wattage, and 49 thermocouples TT-
T-30, HP 3054 scanner and a Pentium 166MMX computer were used to obtain temperature data from each of the radiometers. The LIT data acquisition system handles 500 measuring channels with acquisition at 30 seconds intervals.

\section{RESULTS}


Values of intensity and uniformity of the distribution heat flux absorbed by a radiometer plate imposed by a tungsten filament lamp were obtained by carrying out experimental tests which varied the position of the lamp in relation to its height (coordinate $\mathrm{z}$ ), while maintaining the other positions ( $x$ and $y$ ) fixed, and at the same time varying the wattage of the lamp. The lamp was positioned at distances of $30,35,40,45$ and $50 \mathrm{~cm}$, from the tested radiometer plate using different wattage of 125, 250, 375, 450 and 500 Watts. The relative position of each radiometer on the plate was designated by the coordinates $\mathrm{x}$ and $\mathrm{y}$, whose origin is 0,0 at the center of the plate. Figure 7 shows the position of each radiometer.

The center of the lamp was kept in a central position in relation to the center of the radiometer plate (position $0,0)$, so as to guarantee a better analysis of the results because of the symmetrical effect. Once the temperatures, emissivity of each radiometer was known, it was possible to calculate the absorbed heat flux using equation 1, which considers that the heat flux the radiometer emits is equal to that which it absorbs from the lamp taking into consideration that the heat losses are negligible.

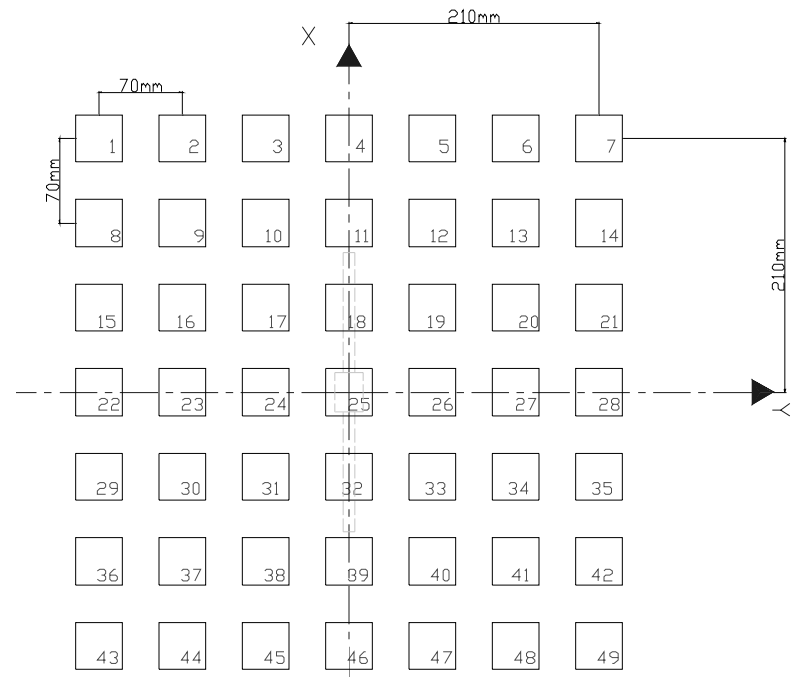

Fig. 7: Positioning of the radiometers.

Figures 8, 9, 10,11 and 12 show the results of the intensity and distribution of absorbed heat flux $(\alpha \mathrm{I})$ by the radiometer plate for a given height $(\mathrm{H})$ and wattage $(\mathrm{P})$.

$$
\alpha I=\varepsilon \sigma T^{4}
$$

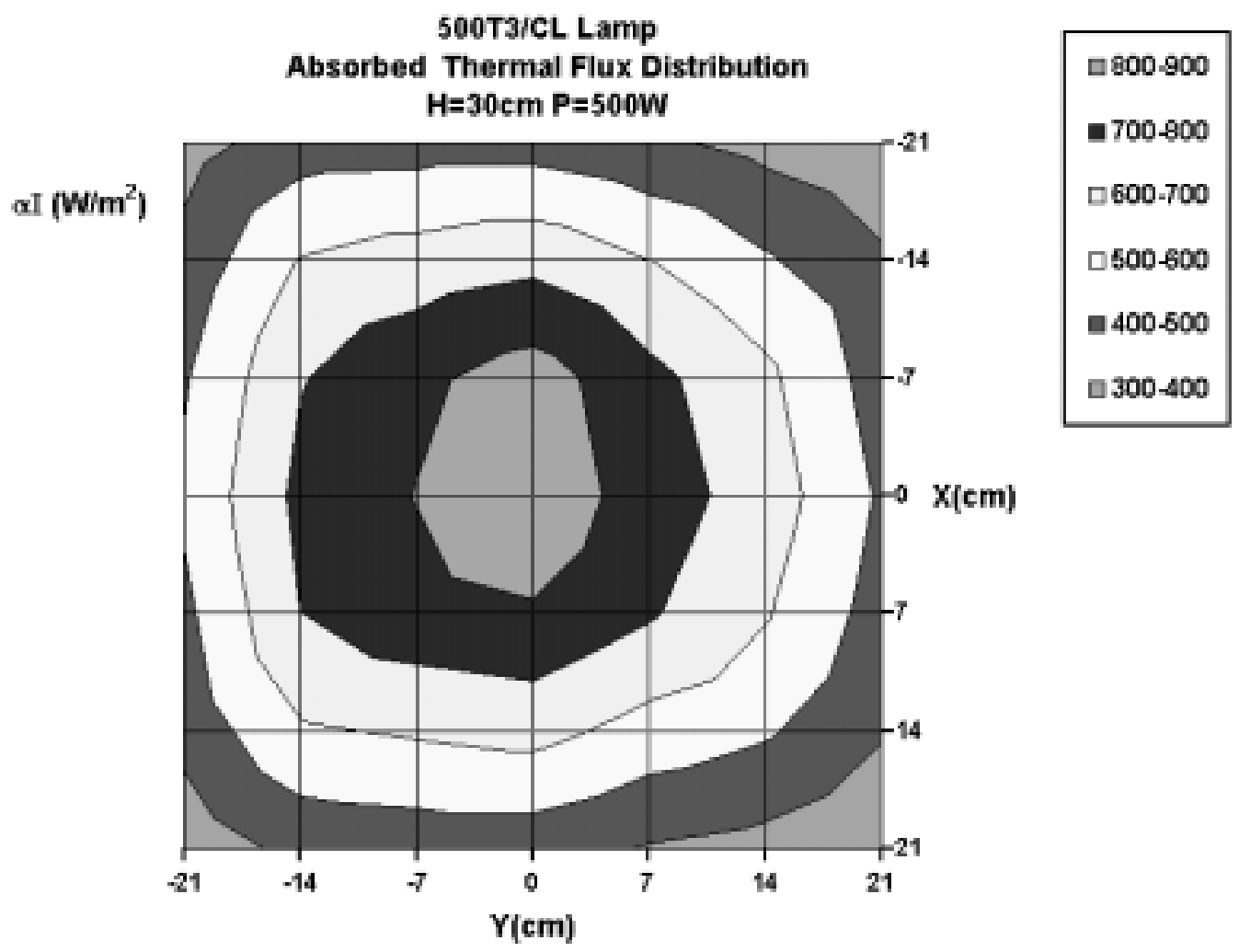

Fig. 8: Absorbed heat flux in the radiometer plate for $\mathrm{H}=30 \mathrm{~cm}$ and $\mathrm{P}=500 \mathrm{~W}$. 
INPE ePrint: sid.inpe.br/yolanda/2004/11.23.09.41 v1 2004-11-24

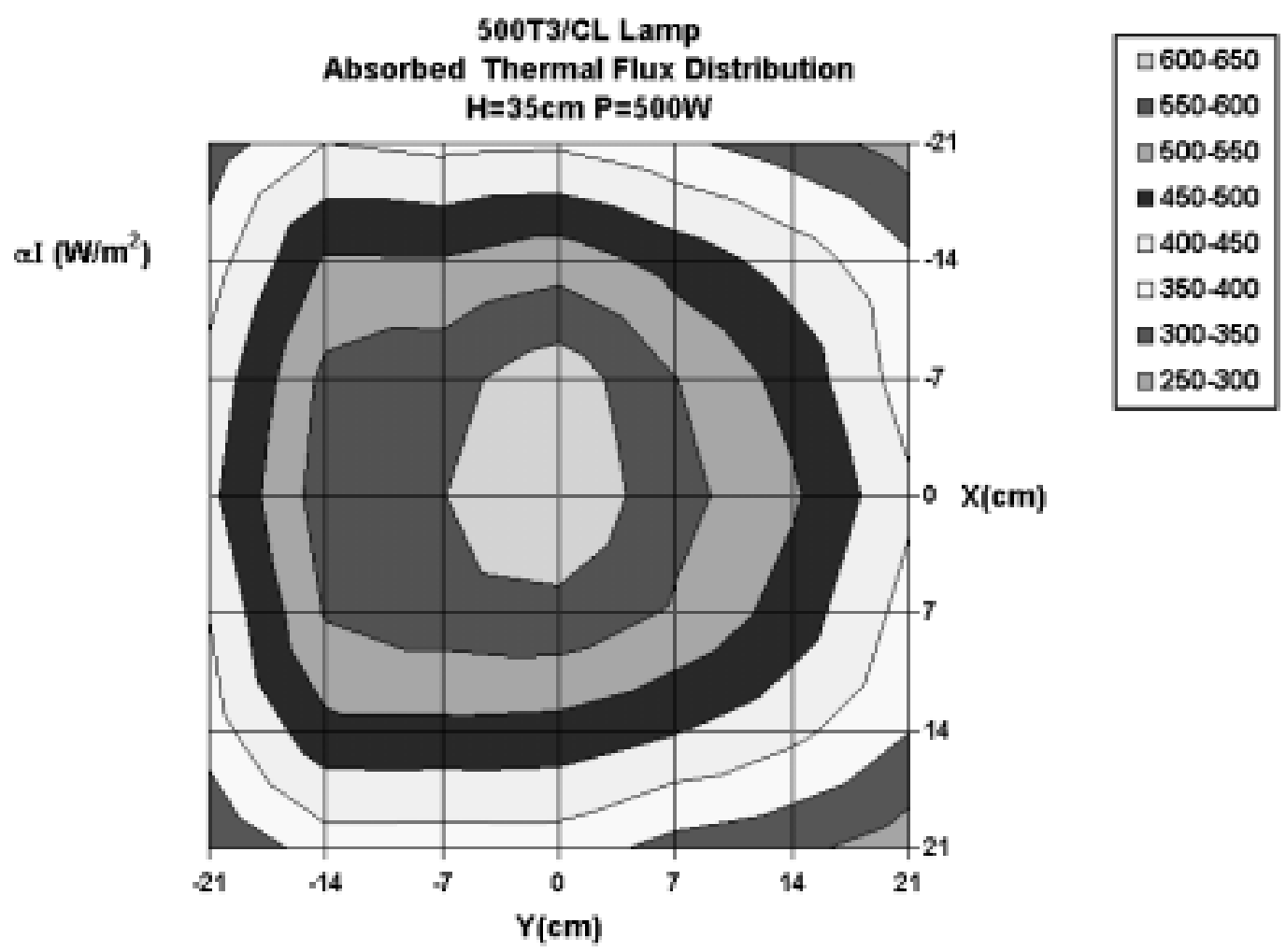

Fig. 9: Absorbed heat flux in the radiometer plate for $\mathrm{H}=35 \mathrm{~cm}$ and $\mathrm{P}=500 \mathrm{~W}$.

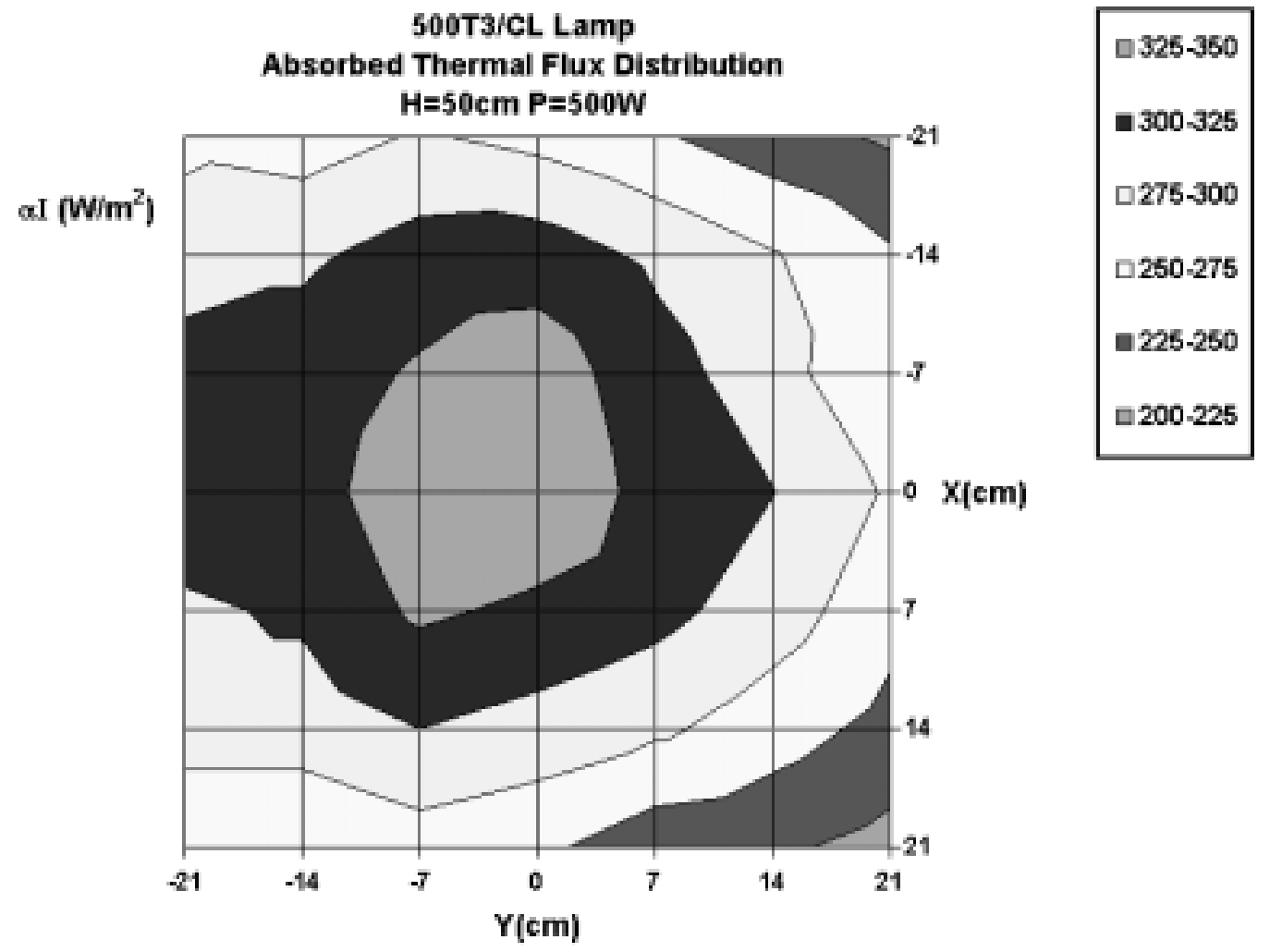

Fig. 10: Absorbed heat flux in the radiometer plate for $\mathrm{H}=50 \mathrm{~cm}$ and $\mathrm{P}=500 \mathrm{~W}$. 
INPE ePrint: sid.inpe.br/yolanda/2004/11.23.09.41 v1 2004-11-24

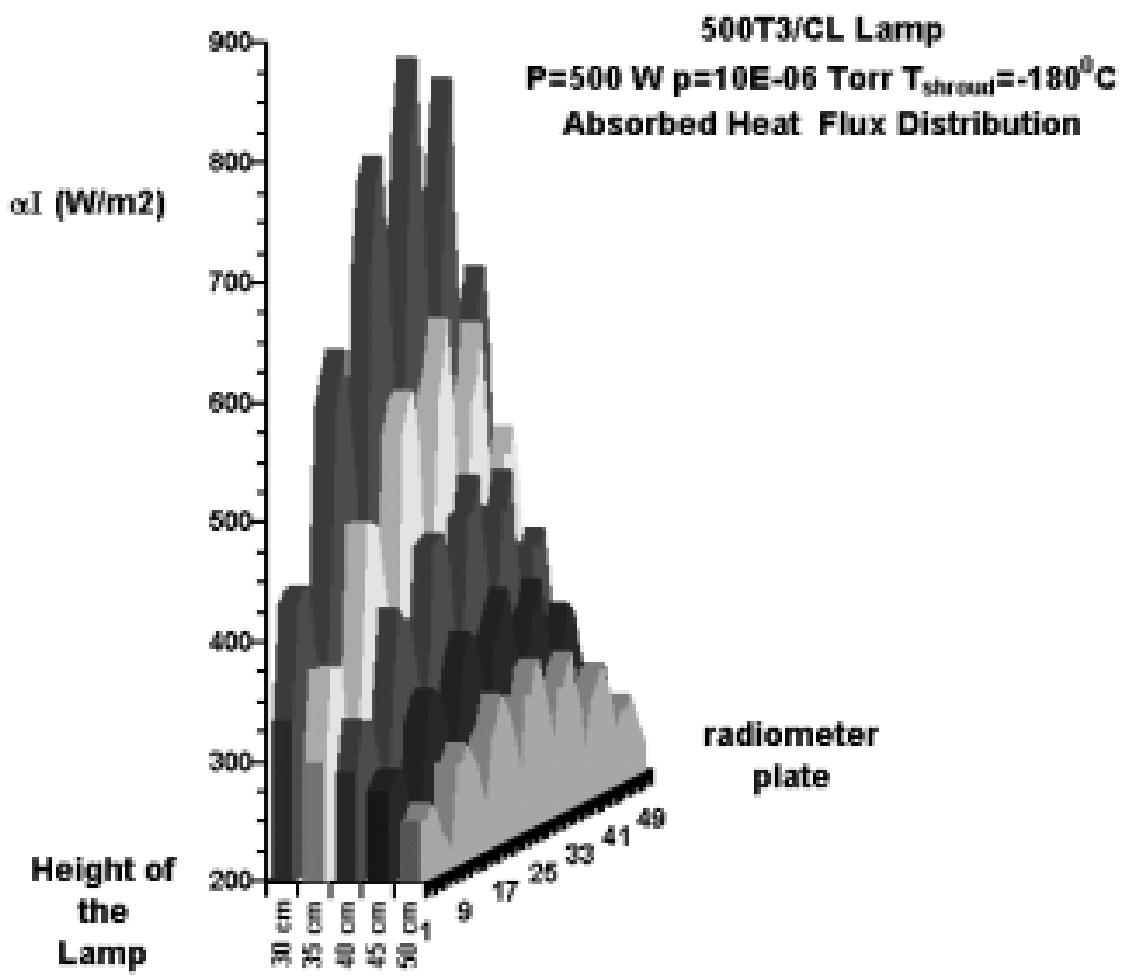

Fig. 11: Absorbed heat flux in the radiometer plate in function of the height of the lamp for $\mathrm{P}=500 \mathrm{~W}$.

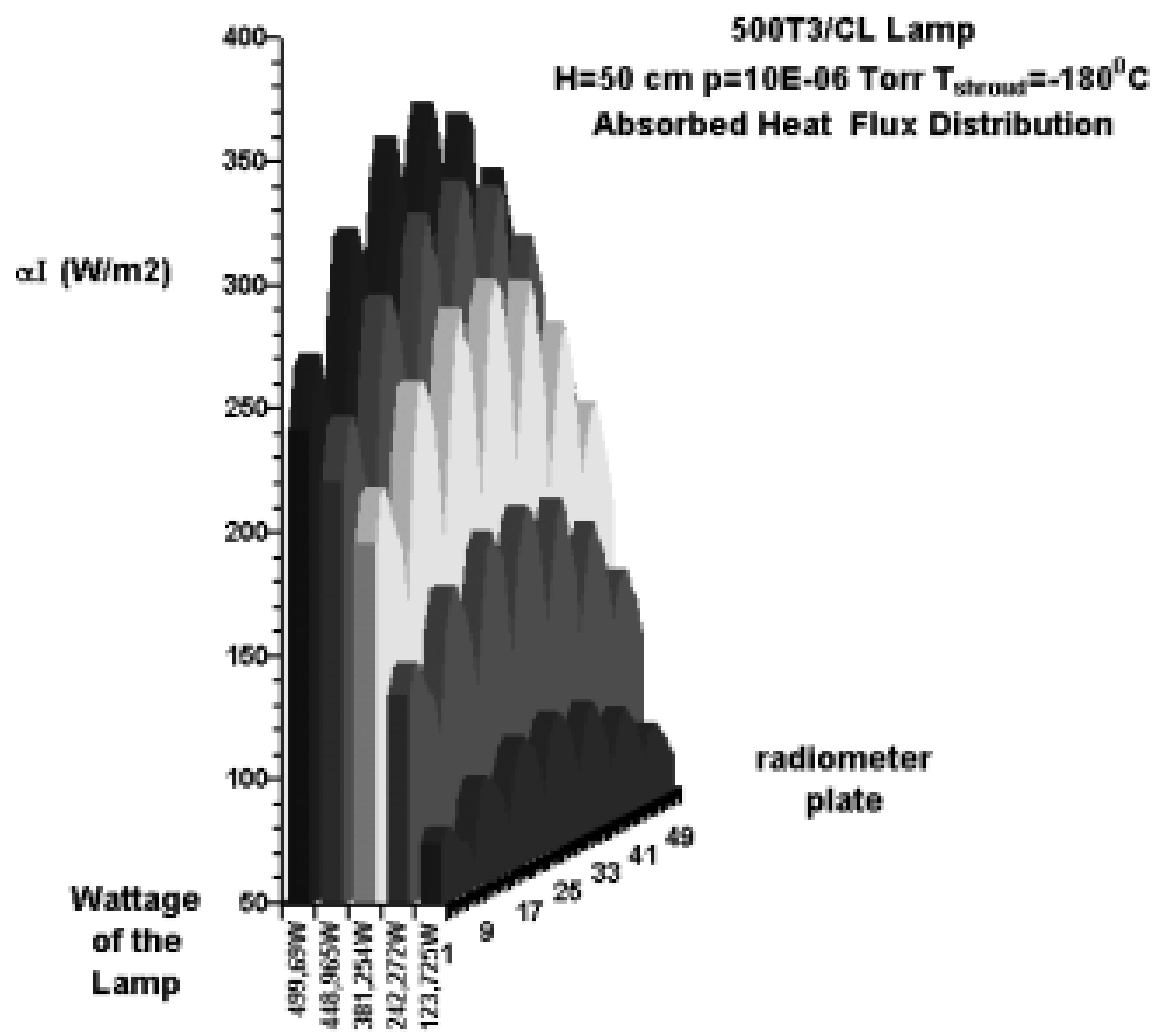

Fig. 12: Absorbed heat flux in the radiometer plate in function of the wattage of the lamp for $\mathrm{H}=50 \mathrm{~cm}$. 


\section{CONCLUSIONS}

Carrying out an analysis of the results it was possible to conclude the following:

- In relation to the variation of the height of the lamp, for a given wattage, a greater intensity of heat flux was obtained for lower values of $\mathrm{H}$ (height), however, there was a poorer distribution of heat flux or in other words a less uniform heat flux field.

- In relation to the variation of the wattage, for $\mathrm{H}$ with better uniformity, an increase in heat flux could be observed corresponding to the increase in wattage.

\section{ACKNOWLEDGEMENTS}

We would like to thank CNPq/RHAE and INPE/LIT for their support in helping us carry out this research and also all the LIT Thermal Vacuum group for their help in manufacturing the experimental apparatus and carrying out of the tests.

\section{REFERENCES}

[1] Braig, A., Schaefer, T. and Pawlowski, P., 1988, "Lessons Learnt from Rosat Thermal Balance Test - A Combined Solar Simulation/Infrared Test", Proceedings of the $3^{\text {rd }}$ European Symposium on Space Thermal Control \& Life Support Systems, Noordwijk, the Netherlands, 3-6 Oct., ESA-SP 288, pp. 443-448.

[2] Cardoso, P. H., Garcia, E. C., 1989, "Simulação do Ambiente Espacial do Satélite SCD-01 por Placas Aquecedoras", X Congresso Brasileiro de Engenharia Mecânica, Anais, Rio de Janeiro, RJ, pp. 581-584.

[3] Kline, S.J. and McClintock, F.A., 1953, "Describing Uncertainties in Single-Sample Experiments", Mechanical Engineering Science, 75(1), pp. 3-8.

[4] Messidoro, P., Boggiatto, D., Pataccia, M., Buratti, P., 1983, "Development of a S/C Infrared Test Technique as an Alternative to Solar Simulation - First Steps on L-SAT Thermal Model", Proceedings of the International Symposium on Environmental and Thermal Systems for Space Vehicles, Toulouse, France, 4-7 Oct., ESA-SP 200, pp. 11-17.

[5] Nuss, H. E., 1987, "Space Simulation Facilities and Recent Experience in Satellite Thermal Testing", Vacuum, Vol. 37, numbers 3/4, Printed in Great Britain, pp. 297-302.
[6] Ramos, F. M., Garcia, E. C., Almeida, J. S., 1988, "Descrição e Análise do Ensaio do Modelo Térmico do Satélite de Coleta de Dados", II Encontro Nacional de Ciências Térmicas (ENCIT), Anais, 06-08 Dez., Águas de Lindóia, SP, pp. 381-384. 